\title{
Alkylating anticancer agents and their relations to microRNAs
}

\author{
Bernhard Biersack \\ Organic Chemistry Laboratory, University of Bayreuth, Bayreuth 95440, Germany.
}

Correspondence to: Dr. Bernhard Biersack, Organic Chemistry Laboratory, University of Bayreuth, Universitätsstrasse 30, Bayreuth 95440, Germany. E-mail: bernhard.biersack@uni-bayreuth.de

How to cite this article: Biersack B. Alkylating anticancer agents and their relations to microRNAs. Cancer Drug Resist2019;2:1-17. http://dx.doi.org/10.20517/cdr.2019.09

Received: 15 Dec 2018 First Decision: 18 Dec 2018 Revised: 17 Jan 2019 Accepted: 25 Jan 2019 Published: 19 Mar 2019

Science Editor: Aamir Ahmad Copy Editor: Cai-Hong Wang Production Editor: Huan-Liang Wu

\begin{abstract}
Alkylating agents represent an important class of anticancer drugs. The occurrence and emergence of tumor resistance to the treatment with alkylating agents denotes a severe problem in the clinics. A detailed understanding of the mechanisms of activity of alkylating drugs is essential in order to overcome drug resistance. In particular, the role of noncoding microRNAs concerning alkylating drug activity and resistance in various cancers is highlighted in this review. Both synthetic and natural alkylating agents, which are approved for cancer therapy, are discussed concerning their interplay with microRNAs.
\end{abstract}

Keywords: Alkylating agents, microRNA, anticancer agents, DNA, drug resistance

\section{INTRODUCTION}

Alkylating agents represent an important tool for the daily fight against cancer. Interestingly, their introduction into clinical application based on chemical warfare. Like a knife that can kill in the hands of an assassin and heal in the hands of a surgeon, the potential of nitrogen and sulfur mustards as anticancer agents was identified after incidents with poison gas (reduction of white blood cells) during World War II and dates back to observations after poison gas attacks during World War $\mathrm{I}^{[1,2]}$. Rational chemical modifications led to less lethal anticancer drug candidates such as melphalan, chlorambucil, and cyclophosphamide (all of them are nitrogen mustards). Alkylation of bionucleophiles (proteins, nucleic acids) mainly occurs at $N$, $O$, and $S$ sites with free electron pairs. In most cases DNA was identified as the main target of alkylating agents and both mono-functional (reaction with only one DNA strand) and bifunctional alkylating agents (reaction with two strands leading to DNA crosslinks) are known ${ }^{[2]}$. Pertinent drug resistance strategies of

cc) (7) The Author(s) 2019. Open Access This article is licensed under a Creative Commons Attribution 4.0 International License (https://creativecommons.org/licenses/by/4.0/), which permits unrestricted use, sharing, adaptation, distribution and reproduction in any medium or format, for any purpose, even commercially, as long as you give appropriate credit to the original author(s) and the source, provide a link to the Creative Commons license, and indicate if changes were made. 
cancers in order to cope with alkylating drugs include elevated glutathione levels, enhanced DNA repair and modified DNA damage signaling, as well as expression of multidrug resistance proteins such as membrane transporters ${ }^{[2]}$. The prodrug temozolomide is a highlight of research concerning alkylating agents because it can penetrate the blood-brain-barrier and is clinically applied for the therapy of glioblastoma ${ }^{[3]}$. Meanwhile, nature has also provided very potent alkylating agents with promising anticancer activities such as mitomycins, cyclopropyl-indoles, and illudins ${ }^{[4-6]}$. Mitomycin C is applied for the treatment of various solid tumors $^{[4]}$. Trabectedin is the latest natural alkylating agent that has been approved for the therapy of soft tissue sarcoma and platinum-resistant ovarian cancer $^{[7]}$.

MicroRNAs (miRNAs) are small RNA molecules of 22-23 nucleotides and regulate numerous genes involved in cell differentiation, cell proliferation, and cell death ${ }^{[8]}$. Mature miRNAs usually bind to the $3^{\prime}$-untranslated region of target messenger RNAs (mRNAs) and one miRNA is able to bind to various mRNAs ${ }^{[9-11]}$. MiRNAs have become valuable tools for the diagnosis and prognosis of cancer diseases due to abnormal expression profiles in cancers ${ }^{[12,13]}$. In addition, miRNAs regulate metastasis formation (epithelial-to-mesenchymal transition) and survival of cancer stem-like cells ${ }^{[14,15]}$. Concerning cancer research, tumor suppressor miRNAs and oncogenic miRNAs (oncomirs) are of particular interest and played crucial roles for the sensitivity and resistance of various tumors to applied $\operatorname{drugs}^{[16]}$. Prominent miRNAs with great relevance to cancer disease are represented by the tumor suppressor let-7 family and the oncomir miR-21 ${ }^{[17,18]}$.

This review intends to give an overview of clinically approved alkylating agents and their interactions with miRNAs in cancer diseases concerning drug activity and resistance.

\section{SYNTHETIC ALKYLATING AGENTS AND THEIR INTERACTIONS WITH MIRNAS}

Synthetic alkylating agents are widely applied for the therapy of solid tumors and of leukemia/lymphoma diseases. Relevant synthetic alkylating agents that are dealt with in this review can be subdivided into the following compound classes: mustards (e.g., nitrogen mustards such as mechlorethamine, melphalan, chlorambucil, bendamustine, cyclophosphamide, estramustine), diazomethane forming prodrugs (e.g., dacarbazine, temozolomide), and $\mathrm{N}$-nitrosoureas (e.g., BCNU/carmustine). The influence of miRNAs on the activity of these alkylating drugs is discussed below.

\section{NITROGEN MUSTARDS, MIRNAS AND CANCER}

As mentioned above, anticancer active nitrogen mustards were developed since 1942 from highly toxic poison gas applied or produced in both World Wars of the 20th century. In order to reduce the systemic toxicity of nitrogen mustard poison gas and of initially applied mustard drugs like mechlorethamine, anilin derivatives such as chlorambucil and melphalan were designed with reduced activity due to their aromatic amine system [Figure 1]. Soon later, bendamustine and the prodrug cyclophosphamide were developed as potent anticancer drugs [Figure 1] ${ }^{[19]}$. In addition, the alkylating estrogen-conjugate estramustine was disclosed [Figure 1] ${ }^{[19]}$. Recent efforts in the field of nitrogen mustard-based anticancer research to increase selectivity and reduce side effects included DNA-targeting strategies, brain-targeting strategies, antibody-directed enzyme prodrug therapy and gene-directed enzyme prodrug therapy strategies, and nitrogen mustard prodrugs activated by glutathione transferase ${ }^{[19]}$. The alkylation mode of action of these 2-chloroethylamino derivatives includes an intramolecular reaction to an aziridium intermediate that readily reacts with bionucleophiles ${ }^{[19]}$. Aside cytotoxic effects on non-malignant cells, genotoxic mutagenic effects were identified for nitrogen mustards as well.

Chlorambucil has been the standard treatment for chronic lymphocytic leukemia (CLL) for decades and the drug is still recommended as a mainstay for the currently widely applied antibody-based chemoimmunotherapy for CLL ${ }^{[20]}$. Chemoresistance of CLL is often mediated by the p53-signaling pathway 
<smiles>N[C@@H](Cc1ccc(N(CCCl)CCCl)cc1)C(=O)O</smiles>

Melphalan<smiles>O=P1(N(CCCl)CCCl)NCCCO1</smiles>

Cyclophosphamide<smiles>O=C(O)CCCc1ccc(N(CCCl)CCCl)cc1</smiles>

Chlorambucil<smiles>CC12CCC3c4ccc(OC(=O)N(CCCl)CCCl)cc4CCC3C1CCC2O</smiles>

Estramustine

Figure 1. Structures of the $N$-mustard alkylating agents melphalan, chlorambucil, cyclophosphamide and estramustine

which plays a crucial role for the cellular response to DNA damage ${ }^{[21]}$. The tumor suppressor microRNA miR-34a is connected with p53-signaling and low expression of miR-34a led to chemoresistance in CLL ${ }^{[22]}$. A considerable number of PCLBCL-LT (primary cutaneous diffuse large B-cell lymphomas, leg-type) patients did not respond to chlorambucil first-line therapy and upregulated expression of the oncogenic miR-17-92 cluster seems responsible leading to suppression of PTEN (phosphatase and TENsin homolog) ${ }^{[23]}$. A miR-210 targeting/inhibiting chlorambucil conjugate was synthesized, which suppressed a cancer relevant hypoxic mechanism and was active against hypoxic triple-negative breast cancer in mice ${ }^{[24]}$. A list of miRNAs associated with chlorambucil activity is provided in Table 1.

Melphalan is a close analog of chlorambucil and has been applied for the treatment of multiple myeloma (MM) since the $1960^{\prime} \mathrm{s}^{[25]}$. From MM patients treated with melphalan circulating exosomal let-7b and miR18a were identified as prognostic factors (i.e., improved survival ${ }^{[26]}$. Suppression of the oncogenes Myc, Ras and CCND1 (cyclin D1) by let-7b may play a role as well as inhibition of the HIF1 $\alpha$-pathway [hypoxiainducible factor (HIF)] by miR-18a ${ }^{[26]}$. IL-6-mediated downregulation of the tumor suppressor miR$15 \mathrm{a} / 16$ expression increased resistance of myeloma cells to melphalan treatment ${ }^{[27]}$. The oncogenic miR221-222 family suppressed p53 upregulated modulator of apoptosis (PUMA) in MM cells leading to drug resistance ${ }^{[28]}$. Inhibition of miR-221 by a 13 mer LNA-i-miR-221 inhibitor broke melphalan resistance in MM by modulation of PUMA (upregulation) and ATP binding cassette C1 (ABCC1) transporter (downregulation) ${ }^{[29]}$. In addition, it was suggested that suppression of miR-451 can enhance the activity of melphalan in multiple myeloma via downregulation of multidrug resistance gene $1(\mathrm{MDR} 1)^{[30]}$. A list of miRNAs involved in melphalan activity in myeloma is given in Table 2.

Cyclophosphamide is one of the most successful anticancer drugs which is still widely applied for the therapy of many cancer diseases 60 years now after its development in the late $1950^{\prime} \mathrm{s}^{[31]}$. The drug is applied for the treatment of breast cancer, childhood cancers, and lymphoma ${ }^{[31]}$. Cyclophosphamide is a prodrug, which can be activated in a chemical or metabolic way. Enzymatic oxidation of cyclophosphamide generates cytotoxic phosphoramide mustard molecules leading to interstrand and intrastrand crosslinks of DNA as well as toxic acrolein which is responsible for the side effects of cyclophosphamide ${ }^{[32]}$. 
Table 1. MiRNAs with effects on the anticancer activity of chlorambucil

\begin{tabular}{llll}
\hline MiRNA & Target & Function & Expression in cancers/tissues \\
\hline miR-34a & p53 & Tumor suppressor & Suppressed in resistant CLL \\
miR-17-92 cluster & PTEN & Oncomir & Upregulated in resistant B-cell lymphoma \\
miR-210 & GPD1L & Oncomir & Upregulated in triple-negative breast cancer \\
\hline
\end{tabular}

CLL: chronic lymphocytic leukemia; GPD1L: glycerol-3-phosphate dehydrogenase 1L; PTEN: phosphatase and TENsin homolog

Table 2. MiRNAs with effects on the anticancer activity of melphalan

\begin{tabular}{llll}
\hline MiRNA & \multicolumn{1}{c}{ Target(s) } & \multicolumn{1}{c}{ Function } & \multicolumn{1}{c}{ Expression in cancers/tissues } \\
\hline let-7b & Myc, Ras, CCND1 & Tumor suppressor & Exosomal let-7b upregulated in sensitive MM \\
miR-15a/16 & - & Tumor suppressor & Suppressed in resistant myeloma \\
miR-18a & HIF1 $\alpha$ & Tumor suppressor & Exosomal miR-18a upregulated in sensitive MM \\
miR-221-222 family & PUMA, ABCC1 & Oncomir & Upregulated in resistant MM \\
miR-451 & MDR1 & Oncomir & Suppressed in resistant MM \\
\hline
\end{tabular}

ABCC1: ATP-binding cassette C1; CCND1: cyclin D1; HIF1 $\alpha$ : hypoxia-inducible facter 1- $\alpha$; MDR1: multidrug resistance gene 1; MM: multiple myeloma; PUMA: p53 upregulated modulator of apoptosis

Clinical sensitivity to cyclophosphamide is strongly correlated with the ability of cancer cells to induce apoptosis upon DNA damage ${ }^{[33]}$. Due to its significance in cancer therapy the relations between miRNAs and cyclophosphamide is well studied, in particular, in lymphoma ${ }^{[34,35]}$. Upregulation of circulating oncogenic miR-125b and miR-130a was determined in B-cell lymphoma samples from patients treated with cyclophosphamide-based chemotherapy ${ }^{[36]}$. In diffuse large B-cell lymphoma (DLBCL, the most common non-Hodgkin lymphoma type) treated with R-CHOP (rituximab, cyclophosphamide, adriamycin, vincristine, and prednisone), increased miR-181a expression prolonged progression free survival (PFS) by suppression of FOXP1 and O6-methylguanine DNA methyltransferase (MGMT) while increased miR-18a levels led to shorter overall survival (OS) and high miR-222 expression to shorter PFS ${ }^{[37]}$. MiR-93 (targets: p21, BCL2L11), miR-221 and miR-222 (target: p27) were upregulated in DLBCL patients with poor outcomes after cyclophosphamide-based therapies ${ }^{[38]}$. Knockdown of the well-known oncomir miR-21 sensitized DLBCL cells to CHOP treatment by upregulation of PTEN ${ }^{[39]}$. Shorter OS was observed from DLBCL patients with high miR-21 expression in the tumor tissue, while high miR-21 levels in the serum promoted relapse free survival ${ }^{[40]}$. Downregulated miR-199a/b also shortened progression free survival time ${ }^{[40]}$. In addition, CHOP or R-CHOP treated DLBCL patients with upregulated miR-200c expression displayed shorter OS than patients with suppressed miR-200 $c^{[41]}$. Induced miR-155 expression was connected with R-CHOP resistance in DLBCL patients although miR-155 sensitized patients to AKT (protein kinase B, ak thymoma) signaling probably by targeting $\mathrm{p} 85 \alpha$ and $\mathrm{SHIP}^{[42]}$. In contrast to that, upregulated expression of miR-129-5p in DLBCL patients treated with CHOP or R-CHOP led to much longer median survival than in patients with downregulated miR-129-5 $\mathrm{p}^{[43]}$. The tumor suppressor miR-146a was downregulated in R-CHOP-treated DBCL patients who displayed drug resistance ${ }^{[44]}$. Suppressed expression of the tumor suppressors miR-146b-5p and miR-320d led to shorter progression free survival in CHOP-treated DLBCL patients $^{[45]}$. Higher serum levels of miR-33a and miR-455-3p indicated better response while high levels of miR-224 (target: CD59), miR-520d-3p and miR-1236 were connected with worse R-CHOP response in DLBCL patients ${ }^{[35,46]}$. Suppressed miR-224 expression in the tumor tissue also indicated poor survival ${ }^{[39]}$. In addition, a higher R-CHOP response rate and longer survival was observed from DLBCL patients with 7q gain, which was attributed to the upregulated expression of miR-25, miR-96, miR-182, and miR-589 ${ }^{[47]}$. Lists of miRNAs involved in cyclophosphamide activity in lymphoma are given in Tables 3 and 4.

MicroRNAs also seem to play a role for drug resistance in breast cancer patients receiving cyclophosphamide as part of the TFAC therapy (paclitaxel, 5-fluorouracil, adriamycin, cyclophosphamide) ${ }^{[48]}$. The tumor suppressor miR-9 bound to the mRNA of human epidermal growth factor 2 (HER2) and increased the response to cyclophosphamide ${ }^{[49]}$. Low expression of let-7, miR-10b, miR-34, miR-155, miR-200c, miR-205, 
Table 3. Effects of oncomirs on the anti-lymphoma activity of cyclophosphamide

\begin{tabular}{ll}
\hline MiRNA & \multicolumn{1}{c}{ Expression (targets) } \\
\hline miR-18 & Upregulated in patients with shorter OS \\
miR-21 & Upregulated in tumor cells and tissues leading to shorter OS (PTEN) \\
miR-93 & Upregulated in resistant patients ( $\mathrm{p} 21, \mathrm{BCL} 2 \mathrm{~L} 11$ ) \\
miR-125b & Upregulated in patients treated with R-CHOP \\
miR-130a & Upregulated in patients treated with R-CHOP \\
miR-155 & Upregulated in R-CHOP-resistant patients ( $\mathrm{p} 85 \mathrm{\alpha}, \mathrm{SHIP1})$ \\
miR-200c & Upregulated in patients with shorter survival \\
miR-221 & Upregulated in resistant patients ( $\mathrm{p} 27$ ) \\
miR-222 & Upregulated in resistant patients with shorter PFS ( $\mathrm{p} 27$ ) \\
miR-224 & Expression in serum connected with worse R-CHOP response \\
miR-52Od-3p & Expression connected with worse R-CHOP response \\
miR-1236 & Expression connected with worse R-CHOP response \\
\hline
\end{tabular}

OS: overall survival; BCL2L11: Bcl2-like protein 11; PTEN: phosphatase and tensin homolog; R-CHOP: rituximab plus cyclophosphamide, hydroxydaunorubicin (doxorubicin), oncovin (vincristine), prednisone; SHIP1: SH2 domain-containing inositol phosphatase 1; PFS: progression free survival

Table 4. Effects of tumor suppressing miRNAs on the anti-lymphoma activity of cyclophosphamide

\begin{tabular}{ll}
\hline MiRNA & \multicolumn{1}{c}{ Expression (targets) } \\
\hline miR-21 & Upregulation in serum promotes survival \\
miR-25 & Expression connected with longer survival in 7q gain patients \\
miR-33a & Expression connected with better R-CHOP response \\
miR-96 & Expression connected with longer survival in 7q gain patients \\
miR-129-5p & Upregulated in patients with longer median survival \\
miR-146a & Suppressed in R-CHOP-resistant patients \\
miR-146b-5p & Suppressed in patients with shorter PFS \\
miR-181a & Upregulated in patients with prolonged PFS (FOXP1, MGMT) \\
miR-182 & Expression connected with longer survival in 7q gain patients \\
miR-199a/b & Suppression connected with shorter PFS \\
miR-224 & Suppression in tumor tissue connected with poor survival \\
miR-320d & Suppressed in patients with shorter PFS \\
miR-455-3p & Expression connected with better R-CHOP response \\
miR-589 & Expression connected with longer survival in 7q gain patients \\
\hline
\end{tabular}

FOXP1: forkhead box protein P1; MGMT: O6-methylguanine DNA methyltransferase; R-CHOP: rituximab plus cyclophosphamide, hydroxydaunorubicin (doxorubicin), oncovin (vincristine), prednisone; PFS: progression free survival

miR-451, and miR-3200 as well as high expression of miR-21, miR-195, and miR-221 were observed after cyclophosphamide treatment ${ }^{[50,51]}$. In particular, expression of the tumor suppressor miR-205 sensitized breast cancer cells to TAC treatment (docetaxel, doxorubicin, cyclophosphamide) by suppression of vascular endothelial growth factor $\mathrm{A}$ and fibroblast growth factor $2^{[52]}$. In contrast to that, miR-663 overexpression was associated with resistance to cyclophosphamide in MDA-MB-231/ADM breast cancer cells (cells resistant to adriamycin) by suppression of heparin sulfate proteoglycan $2^{[53]}$. The MDA-MB-231 cell line is a widely applied model for triple-negative breast cancer (TNBC, i.e., no or reduced expression of estrogen receptor, HER2/neu and progesterone receptor), which is a very problematic form of breast cancer showing chemotherapy resistance and poor prognosis. Samples from cyclophosphamide-treated TNBC patients with good response to chemotherapy exhibited higher miR-20ob-3p (possible targets: PLCB1, MYCN, CCND2, RERG) and miR-190a (possible targets: BCL11A, CALCR, FOXP2, HOXC5) as well as lower miR-512-5p (possible targets: BCL2L2, POLD3, c-Myc) expression when compared with TNBC patients displaying weak chemotherapy response ${ }^{[54]}$. The microRNAs miR-30a, miR-9-3p, miR-770 and miR-143-5p were also identified as markers for chemotherapy response by TNBC patients. Chemotherapy-responding TNBC patients revealed upregulated miR-30a (affected transcriptional regulation in cancer) and miR-9-3p (affected $\mathrm{mTOR} / \mathrm{mammalian}$ target of rapamycin and TGF/transforming growth factor- $\beta$ signaling) as well 
Table 5. MiRNAs with effects on the anti-breast cancer activity of cyclophosphamide

\begin{tabular}{|c|c|c|c|}
\hline MiRNA & Target(s) & Function & Expression \\
\hline let-7 & - & Tumor suppressor & Low expression upon CP treatment \\
\hline miR-9/miR-9-3p & HER2, mTOR and TGF- $\beta$ signaling & Tumor suppressor & Expression increased response to $C P$ \\
\hline miR-10b & - & Tumor suppressor & Low expression upon $\mathrm{CP}$ treatment \\
\hline $\operatorname{miR}-21$ & PTEN & Oncomir & High expression upon CP treatment \\
\hline miR-30a & transcriptional regulation & Tumor suppressor & Upregulation connected with better response \\
\hline $\operatorname{miR}-34$ & - & Tumor suppressor & Low expression upon CP treatment \\
\hline miR-143-5p & $\mathrm{B}$ and $\mathrm{T}$ cell receptor and $\mathrm{mTOR}$ signaling & Oncomir & Suppression connected with better response \\
\hline miR-190a & BCL11A, CALCR, FOXP2, HOXC5 & Tumor suppressor & High expression correlated with better response \\
\hline miR-195 & - & Oncomir & High expression upon CP treatment \\
\hline miR-200b-3p & PLCB1, MYCN, CCND2, RERG & Tumor suppressor & High expression correlated with better response \\
\hline miR-200c & - & Tumor suppressor & Low expression upon $\mathrm{CP}$ treatment \\
\hline miR-205 & VEGFA, FGF2 & Tumor suppressor & $\begin{array}{l}\text { Low expression upon CP treatment, expression } \\
\text { sensitizes to TAC treatment }\end{array}$ \\
\hline miR-221 & PUMA, ABCC1 & Oncomir & High expression upon CP treatment \\
\hline miR-451 & - & Tumor suppressor & Low expression upon CP treatment \\
\hline miR-512-5p & BCL2L2, POLD3, c-Myc & Oncomir & Suppression correlated with better response \\
\hline $\operatorname{miR}-663$ & HSPG2 & Oncomir & Expression connected with resistance of cancer cells \\
\hline miR-770-5p & $\mathrm{B}$ and $\mathrm{T}$ cell receptor signaling & Oncomir & Suppression connected with better response \\
\hline $\operatorname{miR}-3200$ & - & Tumor suppressor & Low expression upon CP treatment \\
\hline
\end{tabular}

ABCC1: ATP-bonding cassette C1; BCL11A: B-cell lymphoma/leukemia 11A; BCL2L2: Bcl-2-like protein 2; CALCR: calcitonin receptor; CCND2: cyclin D2; CP: cyclophosphamide; FGF2: fibroblast growth factor 2; FOXP2: forkhead-box-protein P2; HER2: human epidermal growth factor receptor 2; HSPG2: heparin sulfate proteoglycan 2; mTOR: mammalian target of rapamycin; MYCN: gene coding for N-Myc; POLD3: DNA polymerase delta 3; PTEN: phosphatase and TENsin homolog; PUMA: p53 upregulated modulator of apoptosis; RERG: RASlike estrogen-regulated growth inhibitor; TAC: docetaxel, doxorubicin, cyclophosphamide; TGF- $\beta$ : transforming growth factor $\beta$; VEGFA: vascular endothelial growth factor $\mathrm{A}$

as suppressed miR-770-5p (affected B and T cell receptor signaling) and miR-143-5p (affected B and T cell receptor signaling as well as mTOR signaling $)^{[5]}$. A list of miRNAs involved in cyclophosphamide activity in breast cancer is given in Table 5 .

The relations between miRNAs and cyclophosphamide were also investigated in further cancer diseases. VAC treatment (vindesine, doxorubicin, cyclophosphamide) is applied as a second-line treatment of small cell lung cancer. The structurally simple HDAC inhibitor valproic acid increased the activity of VAC treatment both in vitro and in vivo via induction of miR-589 and suppression of miR-575 expression ${ }^{[56]}$. In addition, overexpression of the oncomirs miR-27b and miR-298 led to cyclophosphamide resistance in Panc1 pancreatic cancer cells by inhibition of vitamin D receptor and cytochrome P3A4 $\left(\mathrm{CYP}_{3} \mathrm{~A} 4\right)^{[57]}$. It became evident that CYP3A4 plays a crucial role for the activation of cyclophosphamide in these cancer cells. A list of miRNAs involved in cyclophosphamide activity in various cancers is given in Table 6 .

Estramustine phosphate is applied for the treatment of advanced prostate cancer and combines the DNAdamaging $N$-mustard scaffold with a tubulin polymerization inhibiting steroid (estradiol-17 $\beta$-phosphate) released upon metabolization of the $\mathrm{drug}^{[58]}$. In prostate cancer cells, estramustine phosphate induced apoptosis via suppression of the oncomir miR-3 ${ }^{[59]}$. In addition, downregulation of the tumor suppressor miR-4319, which suppresses HER2 expression, was associated with poor chemotherapy response in prostate cancer patients and induced miR-4319 expression sensitized prostate cancer cells to estramustine treatment ${ }^{[60]}$. A list of microRNAs involved in estramustine phosphate anticancer activity is given in Table 7.

\section{DACARBAZINE AND TEMOZOLOMIDE, MIRNAS AND CANCER}

Dacarbazine and temozolomide [Figure 2] are valuable anticancer drugs for the treatment of melanoma and of brain tumors such as glioblastomas $(\mathrm{GBMs})^{[6,62]}$. Their mode of action implies the generation of highly toxic DNA-alkylating diazomethane molecules that kill the cancer cells ${ }^{[63]}$. 
<smiles>CN(C)/N=N/c1[nH]cnc1C(N)=O</smiles>

Dacarbazine<smiles></smiles>

Temozolomide

Figure 2. Structures of the alkylating agents dacarbazine and temozolomide

Table 6. MiRNAs with effects on the activity of cyclophosphamide in miscellaneous cancers

\begin{tabular}{llll}
\hline MiRNA & Target & Function & Expression in cancers/tissues \\
\hline miR-27b & CYP3A4, VDR & Oncomir & Overexpression in resistant pancreas cancer cells \\
miR-298 & CYP3A4, VDR & Oncomir & Overexpression in resistant pancreas cancer cells \\
miR-575 & Invasion & Oncomir & Suppression led to sensitive lung cancer cells \\
miR-589 & EMT & Tumor suppressor & High expression led to sensitive lung cancer cells \\
\hline
\end{tabular}

CYP3A4: cytochrome P3A4; EMT: epithelial-to-mesenchymal transition; VDR: vitamin D receptor

Growth inhibition of melanoma cells by dacarbazine was mediated by induction of the expression of miR200 family miRNAs (miR-141, miR-200a/b/c) which regulate apoptosis ${ }^{[64]}$. Dacarbazine is also widely applied for the treatment of lymphomas as part of the ABVD therapy (adriamycin, bleomycin, vinblastine, dacarbazine). Complete response to ABVD therapy was achieved by classical Hodgkin lymphoma patients with reduced miR-494 and miR-1973 plasma levels ${ }^{[65]}$. A list of miRNAs involved in dacarbazine activity in various cancers is given in Table 8.

The development of temozolomide as an anticancer drug started in the 1980's and is a nice example of the productive interplay between chemists, pharmacists and clinicians during the development process ${ }^{[63]}$. Temozolomide is a prodrug and decomposes in aqueous solution. Initially $\mathrm{CO}_{2}$ is released from the molecule whereupon diazomethane is formed that reacts with bionucleophiles ${ }^{[63]}$. The interplay between temozolomide and miRNAs in cancer was thoroughly studied over the last years. Initial studies revealed that temozolomide-induced apoptosis was inhibited by upregulated miR-21 accompanied by decreased Bax/Bcl2 ratio and caspase- 3 activity in GBM cells ${ }^{[6,67]}$. Treatment of GBM cells with temozolomide led to increased miR-21 expression and GBM cells were sensitized to temozolomide by downregulation of miR-21 and miR-17 ${ }^{[68-70]}$. In particular, antisense miR-21 formulated with PLGA [poly(lactic-co-glycolic acid)] nanoparticle carriers increased the anticancer activity of temozolomide against GBM cells ${ }^{[71]}$. Temozolomideresistant GBM cells also exhibited increased miR-10a*, miR-195 (also in cancer stem cells of GMB tumors via mothers against decapentaplegic homolog 2 targeting), and miR-455-3p expression ${ }^{[72,73]}$. However, in melanoma cells, miR-195 functioned as a tumor suppressor by suppression of prohibitin $1^{[74]}$. In addition, chemoresistance to temozolomide was associated with upregulation of miR-9 (targeting/patched homolog 1) in CD133-positive GBM cells and of Bcl-2-interacting mediator of cell death - targeting miR-138 ${ }^{[75-77]}$. Downregulation of the tumor suppressor miR-16 increased Bcl-2 activity and led to temozolomide resistance in glioma cells ${ }^{[78]}$. Suppressed miR-29c expression associated with upregulated reversionless 3-like (REV3L) led to temozolomide resistance in glioma cells ${ }^{[79]}$. In addition, miR-29c enhanced temozolomide activity by indirect suppression of $\mathrm{MGMT}^{[80]}$. MiR-30a expression also enhanced temozolomide activity against U251 GBM cells by inhibition of autophagy and suppression of beclin $1^{[81]}$. Upregulation of the tumor suppressor miR-136 led to higher temozolomide activity in glioma cells by suppression of astrocyte elevated gene 1 $(A E G-1)^{[82]}$. Similarly, induced miR-143 expression increased temozolomide activity against GBM cells via neuroblastoma rat sarcoma oncogene targeting ${ }^{[83]}$. The oncomir miR-93 led to temozolomide resistance of glioma cells by upregulation of $\mathrm{p} 21^{[84]}$. MiR-125b-2 induced temozolomide resistance in glioblastoma 
Table 7. MiRNAs with effects on the anticancer activity of estramustine phosphate

\begin{tabular}{llll}
\hline MiRNA & Target & Function & Expression in cancers/tissues \\
\hline miR-31 & Apoptosis & Oncomir & Suppression in prostate cancer led to apoptosis \\
miR-4319 & HER2 & Tumor suppressor & Suppression in prostate cancer patients led to resistance \\
\hline
\end{tabular}

HER2: human epidermal growth factor receptor 2

Table 8. MiRNAs with effects on the anticancer activity of dacarbazine

\begin{tabular}{llll}
\hline MiRNA & Target & Function & \multicolumn{1}{c}{ Expression in cancers/tissues } \\
\hline miR-141 & Apoptosis & Tumor suppressor & Expression sensitized melanoma cells \\
miR-200a/b/c & Apoptosis & Tumor suppressor & Expression sensitized melanoma cells \\
miR-494 & - & Oncomir & Suppression led to complete response in lymphoma patients \\
miR-1973 & - & Oncomir & Suppression led to complete response in lymphoma patients \\
\hline
\end{tabular}

stem cells was associated with downregulation of Bax and upregulation of Bcl- ${ }^{[85]}$. Downregulation of the oncomirs miR-221/miR-222 refurnished p53 signaling pathway and promoted apoptosis of GBM cells treated with temozolomide ${ }^{[86]}$. MiR-141-3p is another p53-targeting oncomir leading to temozolomide resistance in glioma cells ${ }^{[87]}$. MAP kinase/extracellular-signal regulated kinase (ERK) signaling was induced by the oncomir miR-299-5p, which targeted golgi phosphoprotein 3 and, thus, led to temozolomide resistance in GBM cells ${ }^{[8]}$. Temozolomide resistance in GBM basing on active GSK $3 \beta$ was overcome by upregulated miR$10{ }^{[89]}$. Further to this, miR-128 mediated temozolomide-induced cell death in glioma cells via inhibition of mTOR signaling and suppression of insulin-like growth factor 1, phosphoinositide-3-kinase regulatory subunit 1 , rapamycin-insensitive companion of $\mathrm{mTOR}$ and $\mathrm{mTOR}^{[90]}$. High expression of miR-130a sensitized glioma cells to temozolomide via apurinic/apyrimidinic endonuclease 1 suppression and was upregulated in GBM patients with better response to temozolomide ${ }^{[91]}$. A direct influence on temozolomide resistance was elucidated for miR-181d and miR-603, which suppressed the DNA repair enzyme MGMT leading to greater sensitivity to temozolomide ${ }^{[92]}$. In addition, miR-142-3p promoted temozolomide activity in GBM cells by suppression of MGMT ${ }^{[93]}$. MiR-648 and miR-767-3p were identified as further MGMT targeting/suppressing miRNAs, which enhanced the anticancer activity of temozolomide in T98G GBM cells ${ }^{[94]}$. MiR-182 expression also increased temozolomide activity in GBM cells by apoptosis promotion via c-Met, HIF2A and BCL2L12 suppression ${ }^{[95]}$. However, expression of miR-132 caused temozolomide resistance in GBM cells (U78MG) via downregulation of tumor suppressor candidate $3^{[96]}$. Temozolomideresistant GBM cells and tissues exhibited suppressed miR-370-3p expression levels, which is a tumor suppressor responsible for downregulated MGMT expression and blocked DNA repair ${ }^{[97]}$. In contrast to that, expression of the oncomir miR-423-5p led to temozolomide resistance in glioma cells by targeting ING- $4^{[98]}$. Glioblastoma samples from patients treated with temozolomide revealed upregulated miR-629$3 p$ expression (targeting genes involved in translation and RNA processing) in case of good responders with prolonged $\mathrm{OS}^{[99]}$. The tumor suppressor miR-1268 also sensitized glioma cells (T98G) to temozolomide treatment ${ }^{[100]}$. In addition, miR-1294 suppressed targeting protein for Xenopus kinesin-like protein 2 in glioma cells leading to enhanced temozolomide activity ${ }^{[101]}$. Some miRNAs are special "Janus-type" cases here. Although miR-181b/c are reported as tumor suppressors in GBM, reduced expression of these miRNAs was associated with better temozolomide response ${ }^{[102]}$. And although miR-221 and miR-222 suppress MGMT, their upregulation led to weaker responses to temozolomide ${ }^{[103]}$. In a cancer type dependent way, miR-195 acted either as a tumor suppressor (melanoma) or as an oncomir (GBM, see above). Last but not least, the combination of temozolomide with miRNA-regulating drugs appears promising. For instance, curcumin (a polyphenol isolated from turmeric, Curcuma longa) was able to sensitize GBM cells (C6) to temozolomide via suppression of miR-10b ${ }^{[104]}$. Lists of miRNAs involved in temozolomide anticancer activity are given in Tables 9 and 10.

\section{$N$-nitrosoureas, miRNAs and cancer}

Anticancer active $\mathrm{N}$-nitrosoureas were developed in the course of a screening program initiated by the National Cancer Institute. Starting from the hit compound 1-methyl-3-nitro-1-nitrosoguanidine further 
Table 9. Tumor suppressing miRNAs with effects on the anticancer activity of temozolomide

\begin{tabular}{lll}
\hline MiRNA & Target(s) & \multicolumn{1}{c}{ Expression in cancers/tissues } \\
\hline miR-16 & BCl-2 & Suppression in GBM led to resistance \\
miR-29c & MGMT, REV3L & Suppression in glioma led to resistance \\
miR-30a & Beclin 1 & High expression sensitized glioma cells \\
miR-101 & GSK3 3 & High expression sensitized GBMs \\
miR-128 & IGF1, PIK3R1, RICTOR, mTOR & Expression sensitized glioma cells \\
miR-130a & APE1 & High expression sensitized glioma cells \\
miR-136 & AEG-1 & High expression sensitized glioma cells \\
miR-142-3p & MGMT & Expression sensitized GBM \\
miR-143 & N-RAS & High expression sensitized GBM \\
miR-181d & MGMT & Expression sensitized GBM \\
miR-182 & C-MET, HIF2A, BCL2L12 & High expression sensitized GBM \\
miR-195 & PHB1 & Expression sensitized melanoma \\
miR-370-3p & MGMT & Suppression in resistant GBM \\
miR-603 & MGMT & High expression sensitized GBM \\
miR-629-3p & Translation & High expression in GBM prolonged OS \\
miR-1268 & & Expression sensitized glioma cells \\
miR-1294 & TPX2 & Expression sensitized glioma cells \\
\hline
\end{tabular}

AEG-1: astrocyte elevated gene-1; APE1: apurinic/apyrimidinic endonuclease 1; Bcl-2: B-cell lymphoma 2; GSK3ß: glycogen synthase kinase 3ß; IGF1: insulin-like growth factor 1; MGMT: O6-methylguanine-DNA methyltransferase; mTOR: mammalian target of rapamycin; N-RAS: neuroblastoma rat sarcoma oncogene; PHB1: prohibitin 1; PIK3R1: phosphoinositide-3-kinase regulatory subunit 1; REV3L: reversionless 3-like; RICTOR: rapamycin-insensitive companion of mTOR; TPX2: targeting protein for Xenopus kinesin-like protein 2

analogs were prepared leading to 1-methyl-1-nitrosourea which was active against intracerebrally implanted murine leukemia ${ }^{[105]}$. Further fine-tuning of this compound finally led to carmustine/BCNU (bischloroethylnitrosourea, Figure 3) which entered clinical trials in 1964 and was approved by the FDA in 1977 for the treatment of brain tumors (BCNU passes the blood-brain-barrier because of its lipophilicity), lymphomas and myeloma ${ }^{[106]}$. A newer study recommends the application of BCNU for the treatment of recurrent $\mathrm{GBM}^{[107]}$. $\mathrm{BCNU}$ is a prodrug, which decomposes to afford alkylating chloroethyl moieties that can form DNA interstrand crosslinks ${ }^{[108]}$. Carbamoylation of nucleoprotein lysine residues via isocyanate intermediates can also play a role for the anticancer mode of action of $\mathrm{BCNU}^{[109]}$.

Expression analysis of BCNU-treated glioma cells led to dysregulation of let-7b (tumor suppressor), miR125b-2 (oncomir), miR-133a-1 (tumor suppressor/oncomir), and miR-183 (oncomir) ${ }^{[110]}$. It was also shown that miR-21 expression induced BCNU-resistance in glioma cells via downregulation of Spry2 (sprout homolog 2$)^{[111]}$. Although miR-181d was identified as a tumor suppressor and temozolomide-sensitizing factor (see above), GBM patients with implanted BCNU wafers displayed prolonged overall and progressionfree survival in case of suppressed miR-181d expression ${ }^{[112]}$. In addition, high expression of the oncomir miR-221 suppressed PTEN and led to PI3K/Akt activation and resistance to BCNU ${ }^{[113]}$. A list of miRNAs involved in BCNU anticancer activity is given in Table 11.

\section{NATURAL ALKYLATING AGENTS AND THEIR INTERACTIONS WITH MIRNAS}

Natural alkylating agents were investigated for anticancer activity since the $1950^{\text {' }} \mathrm{s}^{[114,115]}$. Meanwhile, natural alkylating agents are widely applied for the therapy of various cancer diseases. The alkaloids mitomycin C and trabectedin were approved for the therapy of cancer [Figure 4]. The influence of miRNAs on the activity of these natural alkylating drugs is discussed below.

\section{MITOMYCINS, MIRNAS AND CANCER}

Mitomycins are bacterial indole alkaloids. The first mitomycins A and B were isolated in 1956 before mitomycin C was obtained as blue-violet crystals from Streptomyces caespitosus by Japanese groups in $1958^{[116,117]}$. Mitomycin C turned out to be the most anticancer active derivative of this group of mitomycins 
<smiles>O=NN(CCCl)C(=O)NCCCl</smiles>

\section{Carmustine/BCNU}

Figure 3. Structure of the N-nitrosourea alkylating drug carmustine/BCNU

Table 10. Oncomirs with effects on the anticancer activity of temozolomide

\begin{tabular}{lll}
\hline MiRNA & Target(s) & \multicolumn{1}{c}{ Expression in cancers/tissues } \\
\hline miR-9 & PTCH1 & High expression in resistant GBM \\
miR-10* & - & High expression in resistant GBM \\
miR-10b & - & Suppression sensitized GBM cells \\
miR-17 & ATG7 & Suppression sensitized GBM cells \\
miR-21 & Bax/Bcl2 & Suppression sensitized GBM cells \\
miR-93 & p21 & Expression correlated with resistance in glioma cells \\
miR-125b-2 & Bax & Expression correlated with glioblastoma stem cell resistance \\
miR-132 & TUSC3 & Expression correlated with resistance in GBM cells \\
miR-138 & BIM & High expression in resistant GBM \\
miR-141-3p & p53 & Expression correlated with resistance in glioma cells \\
miR-195 & - & High expression in resistant GBM \\
miR-221 & p53 & Suppression promotes apoptosis in GBM cells \\
miR-222 & p53 & Suppression promotes apoptosis in GBM cells \\
miR-299-5p & GOLPH3 & Expression correlated with resistance in GBM cells \\
miR-423-5p & ING-4 & Expression correlated with resistance in glioma cells \\
miR-455-3p & SMAD2 & High expression in resistant GBM \\
\hline
\end{tabular}

ATG7: autophagy-related protein 7; Bax: Bcl-2-associated X protein; Bcl-2: B-cell lymphoma 2; BIM: BCL-2-interacting mediator of cell death; GOLPH3: golgi phosphoprotein 3; ING-4: inhibitor of growth protein 4; PTCH1: patched homolog 1; SMAD2: mothers against decapentaplegic homolog 2; TUSC3: tumor suppressor candidate 3

and entered clinical trials in Japan shortly after its discovery ${ }^{[18]}$. Currently, it is applied for the treatment of localized bladder cancer, anal cancer, head-and-neck cancer, and breast cancer (palliative 2nd or 3rd line treatment ${ }^{[119]}$. Mitomycin $\mathrm{C}$ is a prodrug and activated mitomycin $\mathrm{C}$ forms DNA crosslinks that are highly lethal to cancer cells ${ }^{[120]}$. Activation of mitomycin C occurs via reduction of the benzoquinone scaffold to a hydroquinone (a reaction catalyzed by enzymes such as DT-diaphorase). Subsequent elimination of methanol forms a reactive aziridine system, which reacts with DNA via aziridine ring opening. Elimination of carbamate enables a second alkylating step leading to DNA crosslinking ${ }^{[120]}$.

Transfection of HT-29 colon cancer cells with let-7-1 suppressed COP9 signalosome expression and increased mitomycin C activity ${ }^{[121]}$. Expression of the tumor suppressor miR-31 enhanced the tumor growth inhibition of urothelial bladder cancer by mitomycin $\mathrm{C}$ both in vitro and in vivo ${ }^{[122]}$. MiR-31 inhibited integrin $\alpha 5$ directly and suppressed Akt and ERK signaling ${ }^{[122]}$. In addition, miR-34a expression sensitized medulloblastoma to mitomycin $\mathrm{C}$ treatment by downregulation of melanoma antigen $\mathrm{A}$ and upregulation of $\mathrm{p} 53^{[123]}$. In contrast to that, inhibition of miR-191-5p expression led to higher mitomycin C activity against breast cancer cells

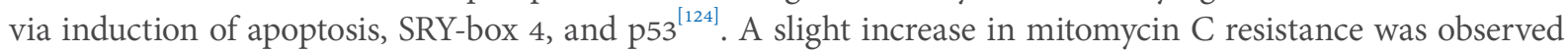
for Snail-expressing mesenchymal MCF-7 breast cancer cells, which displayed suppressed miR-200 family expression $^{[125]}$. Mitomycin C was shown to induce senescence in human mesenchymal stem cells via upregulation of the tumor suppressor aminoacyl-tRNA synthetase-interacting multifunctional protein $3 /$ p18, and suppression of AIMP3/p18 was observed for miR-543 and miR-590-3p ${ }^{[126]}$. This mechanism may also play a role for the anticancer activity of mitomycin C. Oxaliplatin-resistant HCT-116/l-OHP colon cancer cells 
<smiles>COC12CNC(CN1)N2C1=C(C=O)C(=O)C(N)=C(C)C1=O</smiles>

Mitomycin C

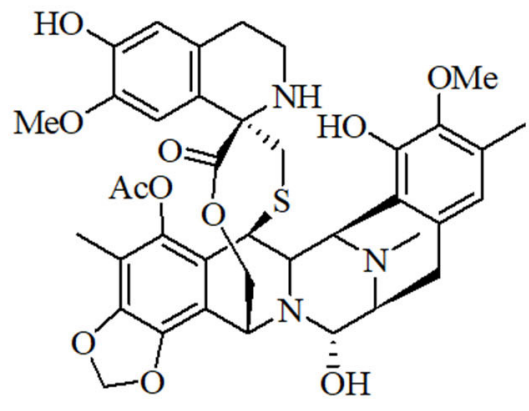

Trabectedin

Figure 4. Structures of the natural alkylating agents mitomycin $C$ and trabectedin

Table 11. MiRNAs with effects on the anticancer activity of BCNU

\begin{tabular}{llll}
\hline MiRNA & Target & \multicolumn{1}{c}{ Function } & Expression in cancers/tissues \\
\hline let-7b & - & Tumor suppressor & Dysregulated in glioma cells upon BCNU treatment \\
miR-21 & Spry2 & Oncomir & Expression in glioma cells induced resistance \\
miR-125b-2 & - & Oncomir & Dysregulated in glioma cells upon BCNU treatment \\
miR-133-1 & - & Oncomir/tumor suppressor & Dysregulated in glioma cells upon BCNU treatment \\
miR-181d & - & Oncomir & Suppression led to prolonged survival of GBM patients \\
miR-183 & - & Oncomir & Dysregulated in glioma cells upon BCNU treatment \\
miR-221 & PTEN & Oncomir & High expression in GBM induced resistance \\
\hline
\end{tabular}

PTEN: phosphatase and TENsin homolog; Spry2: sprouty homolog 2

transfected with miR-1915 mimics revealed enhanced mitomycin C sensitivity by suppression of Bcl-2 ${ }^{[127]}$. A list of miRNAs involved in mitomycin $\mathrm{C}$ anticancer activity is given in Table 12 .

Since mitomycin C is a DNA-damaging drug, its long-term genotoxic effects and the inheritable aberration of miRNA expression induced by mitomycin $\mathrm{C}$ were investigated. Indeed, the treatment of HeLa cells with mitomycin C exhibited upregulated inherited expression of oncomirs such as miR-19b-3p, miR-21-3p, miR30a-3p, miR-30e-3p, and miR-182-5p as well as suppressed inherited expression of the tumor suppressors miR-23b-3p, miR-29b-3p, miR-99a-5p, miR-99b-5p, miR-100-5p, miR-148a-3p, miR-193a-3p, ,iR-340-5p, and miR-365-3p ${ }^{[128]}$. It is possible that new tumors can form basing on the long-term effects of mitomycin $\mathrm{C}$ and the observed aberrant miRNA expression.

\section{TRABECTEDIN, MIRNAS AND CANCER}

Trabectedin (ecteinascidin 743, Yondelis ${ }^{\circ}$ ) is a rather new natural alkylating agent that belongs to the class of tetrahydroisoquinoline alkaloids. It was isolated from the Caribbean tunicate Ecteinascidia turbinata, which is only the host of the trabectedin-producing symbiont Endoecteinascidia frumentensis ${ }^{[129]}$. The high anticancer activity of trabectedin led to its clinical approval for the treatment of soft tissue sarcoma ${ }^{[129]}$. The unique DNA-damaging mechanism of trabectedin includes binding to nitrogen-N2 of guanine DNA bases in the minor groove. This DNA-trabectedin adduct interacts with DNA repair proteins of the transcriptioncoupled nucleotide excision repair DNA-repair system which causes cell death via the formation of doublestrand breaks mainly in homologous recombination-deficient cells ${ }^{[129]}$. This mechanism is almost unique among known alkylating agents and only illudins have revealed a similar mode of action ${ }^{[130]}$. Trabectedin also blocked the transcriptional activity of fused in sarcoma-C/EBP-homologous protein (FUS-CHOP) ${ }^{[131]}$. The difference in miRNA expression between trabectedin-sensitive and trabectedin-resistant myxoid liposarcoma cells (402-91 sensitive and 402-91/ET trabectedin-resistant cells) was investigated and the resistant cells showed two-fold higher miR-21 expression (target: PDCD4/programmed cell death 4) as well 
Table 12. MiRNAs with effects on the anticancer activity of mitomycin C

\begin{tabular}{llll}
\hline MiRNA & \multicolumn{1}{c}{ Target } & Function & \multicolumn{1}{c}{ Expression in cancers/tissues } \\
\hline let-7-1 & CSN & Tumor suppressor & Transfection sensitized colon cancer cells \\
miR-31 & ITGA5 & Tumor suppressor & Expression sensitized urothelial bladder cancer \\
miR-34a & MAGE-A, p53 & Tumor suppressor & Expression sensitized medulloblastoma \\
miR-191-5p & SOX4 & Oncomir & Suppression sensitized breast cancer \\
miR-200 & Zeb1, Zeb2, Slug & Tumor suppressor & Suppression correlated with resistance of breast cancer cells \\
miR-543 & AIMP3/p18 & Oncomir & Expression in mesenchymal stem cells blocked senescence \\
miR-590-3p & AIMP3/p18 & Oncomir & Expression in mesenchymal stem cells blocked senescence \\
miR-1915 & Bcl-2 & Tumor suppressor & Transfection sensitized colon cancer cells \\
\hline
\end{tabular}

AIMP3: aminoacyl-tRNA synthetase-interacting multifunctional protein 3; Bcl-2: B-cell lymphoma 2; CSN: COP9 signalosome; ITGA5: integrin a5; MAGE-A: melanoma antigen A; Slug: Snail homolog; Zeb1/2: zinc finger E-box homeobox 1/2; SOX4: SRY-box 4

Table 13. MiRNAs with effects on the anticancer activity of trabectedin

\begin{tabular}{|c|c|c|c|}
\hline MiRNA & Target & Function & Expression in cancers/tissues \\
\hline let-7c & - & Tumor suppressor & Suppression in cholangiocarcinoma upon trabectedin treatment \\
\hline let-7e & CCND1, E2F5, SEMA4C & Tumor suppressor & Suppression in 402-91/ET cells led to resistance \\
\hline miR-7 & FUS-CHOP & Oncomir & Upregulation in 402-91/ET cells led to resistance \\
\hline miR-21 & PDCD4 & Oncomir & $\begin{array}{l}\text { Upregulation in 402-91/ET cells led to resistance, suppression in } \\
\text { cholangiocarcinoma upon trabectedin treatment }\end{array}$ \\
\hline $\operatorname{miR}-98$ & - & Tumor suppressor & Suppression in 402-91/ET cells led to resistance \\
\hline miR-130a & FUS-CHOP & Tumor suppressor & Suppression in 402-91/ET cells led to resistance \\
\hline miR-192 & - & Tumor suppressor & Suppression in 402-91/ET cells led to resistance \\
\hline miR-214-3p & TWIST & Tumor suppressor & Suppression in cholangiocarcinoma upon trabectedin treatment \\
\hline miR-331-3p & EMT & Oncomir & Suppression in cholangiocarcinoma upon trabectedin treatment \\
\hline miR-375 & $\mathrm{PI} 3 \mathrm{~K} / \mathrm{Akt}$ & Tumor suppressor & Upregulation in cholangiocarcinoma upon trabectedin treatment \\
\hline $\operatorname{miR}-494-3 p$ & - & Oncomir & Upregulation in cholangiocarcinoma upon trabectedin treatment \\
\hline miR-4284 & - & Tumor suppressor & Upregulation in cholangiocarcinoma upon trabectedin treatment \\
\hline
\end{tabular}

CCND1: cyclin D1; E2F5: E2F transcription factor 5; EMT: epithelial-to-mesenchymal transition; FUS-CHOP: fused in sarcoma-C/EBPhomologous protein; PDCD4: programmed cell death 4; PI3K/Akt: phosphatidylinositol-4,5-bisphosphate 3-kinase/ak thymoma; SEMA4C: semaphoring-4C; TWIST: twist transcription factor

as three-fold lower let-7e expression (targets: CCND1, E2F5, SEMA4C) ${ }^{[132]}$. The oncomir miR-7 was also upregulated while the tumor suppressors miR-98, miR-130a and miR-192 were suppressed in the resistant 402-91/ET cells ${ }^{[132]}$. The miRNAs miR-7, miR-21 and miR-130a probably act via FUS-CHOP since these miRNAs have CHOP-binding motifs ${ }^{[132]}$. In cholangiocarcinoma, trabectedin treatment led to upregulation of the oncomir miR-494-3p ${ }^{[133]}$. In addition, the tumor suppressors let-7c and miR-214-3p were suppressed ${ }^{[133]}$. Interestingly, trabectedin downregulated the oncomirs miR-21-3p, miR-21-5p, and miR-331-3p (oncomir in HCC), and upregulated the tumor suppressors miR-375 (tumor suppressor in colon and pancreatic cancer) and miR-4284 (tumor suppressor in glioblastoma), which may be a reason for the relatively high activity of trabectedin in this cancer model ${ }^{[133]}$. A list of miRNAs involved in trabectedin anticancer activity is given in Table 13.

\section{CONCLUSION}

Alkylating drugs still play a crucial role for the therapy of various cancer diseases. While some examples are only applied for the treatment of special tumors (e.g., estramustine for the treatment of prostate cancer), other drugs (e.g., cyclophosphamide) are widely applied. The anticancer activity of these alkylating agents is regulated by various cellular factors. Aside proteins, small RNA molecules called miRNAs revealed a crucial role for the outcome of therapies based on alkylating drugs. Vice versa, alkylating drugs can also regulate miRNA expression leading to enhanced sensitivity of the affected cancer. Thus, a detailed understanding of the interplay between alkylating drugs and miRNAs is crucial for the development of new and improved cancer therapies. In particular, combination therapies with alkylating agents should be carefully checked in 
view of the corresponding miRNAs involved in alkylating drug response and resistance, and the co-drugs for combination therapies with these alkylating agents should be selected accordingly. Prolonged survival and improved quality of life would be possible and conceivable prospects for many cancer patients.

\section{DECLARATIONS}

\section{Authors' contributions}

The author contributed solely to the article.

\section{Availability of data and materials}

Not applicable.

\section{Financial support and sponsorship}

None.

\section{Conflicts of interest}

The author declared that there are no conflicts of interest.

\section{Ethical approval and consent to participate}

Not applicable.

\section{Consent for publication}

Not applicable.

\section{Copyright}

(c) The Author(s) 2019.

\section{REFERENCES}

1. Smith SL. War! What is it good for? Mustard gas medicine. CMAJ 2017;189:E321-2.

2. Ralhan R, Kaur J. Alkylating agents and cancer therapy. Expert Opin Ther Patents 2007;17:1061-75.

3. Baker SD, Wirth M, Statkevich P, Reidenberg P, Alton K, et al. Absorption, metabolism, and excretion of 14C-temozolomide following oral administration to patients with advanced cancer. Clin Cancer Res 1999;5:309-17.

4. Bradner WT. Mitomycin C: a clinical update. Cancer Treat Rev 2001;27:35-50.

5. Ghosh N, Sheldrake HM, Searcey M, Pors K. Chemical and biological explorations of the family of CC-1065 and the duocarmycin natural products. Curr Topics Med Chem 2009;9:1494-524.

6. Schobert R, Knauer S, Seibt S, Biersack B. Anticancer active illudins: recent developments of a potent alkylating compound class. Curr Med Chem 2011;18:790-807.

7. Carter NJ, Keam SJ. Trabectedin: a review of its use in soft tissue sarcoma and ovarian cancer. Drugs 2010;70:355-76.

8. Guarnieri DJ, DiLeone RJ. MicroRNAs: a new class of gene regulators. Ann Med 2008;40:197-208.

9. Bartels DB. MicroRNAs: genomics, biogenesis, mechanism, and function. Cell 2004;116: 281-98.

10. Wu S, Huang J, Ding Y, Zhao L, Liang L, et al. Multiple microRNAs modulate p21Cip1/Waf1 expression by directly targeting its 3' untranslated region. Oncogene 2010;29:2302-8.

11. Calin GA, Croce CM. MicroRNA signatures in human cancers. Nat Rev Cancer 2006;6:857-66.

12. Mallick R, Patnaik SK, Yendumuri S. Micro RNAs and lung cancer: biology and prognosis in diagnosis and prognosis. J Carcinog 2010;9:8.

13. Rothe F, Ignatiadis M, Chaboteaux C, Haibe-Kains B, Kheddoumi N, et al. Global microRNA expression profiling identifies miR-210 associated with tumor proliferation, invasion and poor clinical outcome in breast cancer. PLoS One 2011;6:e20980.

14. Shimono Y, Zabala M, Cho RW, Lobo N, Dalerba P, et al. Downregulation of miRNA-200c links breast cancer stem cells with normal cells. Cell 2009;138:592-603.

15. Gregory PA, Bracken CP, Bert AG, Godall GJ. MicroRNAs as regulators of epithelial-mesenchymal transition. Cell Cycle 2008;7:3112-8.

16. Biersack B. Interactions between anticancer active platinum complexes and non-coding RNAs/microRNAs. Non-coding RNA Res 2017;2:1-17.

17. Su JL, Chen PS, Johansson G, Kuo ML. Function and regulation of let-7 microRNAs. MicroRNA 2012;1:34-9.

18. Feng YH, Tsao CJ. Emerging role of microRNA-21 in cancer. Biomed Rep 2016;5:395-402. 
19. Singh RK, Kumar S, Prasad DN, Bhardwai TR. Therapeutic journey of nitrogen mustards alkylating anticancer agents: historic to future perspectives. Eur J Med Chem 2018;151:401-33.

20. Goede V, Eichhorst B, Fischer K, Wendtner CM, Hallek M. Past, present and future role of chlorambucil in the treatment of chronic lymphocytic leukemia. Leuk Lymphoma 2015;56:1585-92.

21. Zenz T, Mohr J, Edelmann J, Sarno A, Hoth P, et al. Treatment resistance in chronic lymphocytic leukemia: the role of the p53 pathway. Leuk Lymphoma 2009;50:510-3.

22. Zenz T, Mohr J, Eldering E, Kater AP, Bühler A, et al. MiR-34a as part of the resistance network in chronic lymphocytic leukemia. Blood 2009; 113:3801-8.

23. Battistella M, Romero M, Castro-Vega LJ, Gapihan G, Bouhidel F, et al. The high expression of the microRNA 17-92 cluster and its paralogs, and the downregulation of the target gene PTEN, is associated with primary cutaneous B-cell lymphoma progression. J Invest Dermatol 2015;135:1659-67.

24. Costales MG, Haga CL, Velagapudi SP, Childs-Disney JL, Phinney DG, et al. Small molecule inhibition of microRNA-210 reprograms an oncogenic hypoxic circuit. J Am Chem Soc 2017;139:3446-55.

25. Zweegman S, Huijgens PC. Treatment of myeloma: recent developments. Anticancer Drugs 2002;13:339-51.

26. Manier S, Liu CJ, Avet-Loiseau H, Park J, Shi J, et al. Prognostic role of circulating exosomal miRNAs in multiple myeloma. Blood 2017;129:2429-36.

27. Hao M, Zhang L, An G, Sui W, Yu Z, et al. Suppressing miRNA-15a/16 expression by interleukin-6 enhances drug-resistance in myeloma cells. J Hematol Oncol 2011;4:37.

28. Zhao JJ, Chu ZB, Hu Y, Lin J, Wang J, et al. Targeting the miR-221-222/PUMA/BAK/BAX pathway abrogates dexamethasone resistance in multiple myeloma. Cancer Res 2015;75:4384-97.

29. Gullá A, Di Martino MT, Cantafio MEG, Morelli E, Amodio N, et al. A 13 mer LNA-i-miR-221 inhibitor restores drug sensitivity in melphalan-refractory multiple myeloma cells. Clin Cancer Res 2015;22:1222-33.

30. Du J, Liu S, He J, Liu X, Qu Y, et al. MicroRNA-451 regulates stemness of side population cells via PI3K/Akt/mTOR signaling pathway in multiple myeloma. Oncotarget 2015;6:14993-5007.

31. Emadi A, Jones RJ, Brodsky RA. Cyclophosphamide and cancer: golden anniversary. Nat Rev Clin Oncol 2009;6:638-47.

32. Boddy AV, Yule SM. Metabolism and pharmacokinetics of oxazaphosphorines. Clin Pharmacokinet 2000;39:291-304.

33. Zhang J, Tian Q, Chan SY, Duan W, Zhou S. Insights into oxaphosphorine resistance and possible approaches to its circumvention. Drug Resist Updat 2005;8:271-97.

34. Cho WCS. Great potential of microRNAs as predictive and prognostic markers for cancer. Expert Rev Mol Diagn 2012;12:315-8.

35. Yu X, Li Z. New insights into microRNAs involves in drug resistance in diffuse large B cell lymphoma. Am J Transl Res 2015;7:2536-42.

36. Yuan WX, Gui YX, Na WN, Chao J, Yang X. Circulating microRNA-125b and microRNA-130a expression profiles predict chemoresistance to R-CHOP in diffuse large B-cell lymphoma patients. Oncol Lett 2016;11:423-32.

37. Alencar AJ, Malumbres R, Kozloski GA, Advani R, Talreja N, et al. MicroRNAs are independent predictors of outcome in diffuse large B-cell lymphoma patients treated with R-CHOP. Clin Cancer Res 2011;17:4125-35.

38. Montes-Moreno S, Martinez N, Sanchez-Espiridión B, Uriarte RD, Rodriguez ME, et al. MiRNA expression in diffuse large B-cell lymphoma treated with chemoimmunotherapy. Blood 2011;118:1034-40.

39. Bai H, Wei J, Deng C, Yang X, Wang C, et al. MicroRNA-21 regulates the sensitivity of diffuse large B-cell lymphoma cells to the CHOP chemotherapy regimen. Int J Hematol 2013;97:223-31.

40. Zheng Z, Li X, Zhu Y, Gu W, Xie X, et al. Prognostic significance of miRNA in patients with diffuse large B-cell lymphoma: a metaanalysis. Cell Physiol Biochem 2016;39:1891-904.

41. Berglund M, Hedstrom G, Amini RM, Enblad G, Thunberg U. High expression of microRNA-200c predicts poor clinical outcome in diffuse large B-cell lymphoma. Oncol Rep 2013;29:720-4.

42. Iqbal J, Shen Y, Huang X, Liu Y, Wake L, et al. Global microRNA expression profiling uncovers molecular markers for classification and prognosis in aggressive B-cell lymphoma. Blood 2015;125:1137-45.

43. Hedstrom G, Thunberg U, Berglund M, Simonsson M, Amini RM, et al. Low expression of microRNA-129-5p predicts poor clinical outcome in diffuse large B cell lymphoma (DLBCL). Int J Hematol 2013;97:465-71.

44. Huang H, Gu J, Yao S, Yao Z, Zhao Y, et al. MicroRNAs are related to rituximab with cyclophosphamide, doxorubicin, vincristine, and prednisone resistance in patients with diffuse large B-cell lymphoma. Cancer Transl Med 2015;1:6-10.

45. Wu PY, Zhang XD, Zhu J, Guo XY, Wang JF. Low expression of microRNA-146b-5p and microRNA-320d predicts poor outcome of large B-cell lymphoma treated with cyclophosphamide, doxorubicin, vincristine, and prednisone. Hum Pathol 2014;45:1664-73.

46. Song G, Gu L, Li J, Tang Z, Liu H, et al. Serum microRNA expression profiling predict response to R-CHOP treatment in diffuse large B cell lymphoma patients. Ann Hematol 2014;93:1735-43.

47. Chigrinova E, Mian M, Shen Y, Greiner TC, Chan WC, et al. Integrated profiling of diffuse large B-cell lymphoma with 7q gain. Br J Haematol 2011;153:499-503.

48. Salter KH, Acharya CR, Walters KS, Redman R, Anguiano A, et al. An integrated approach t the prediction of chemotherapeutic response in patients with breast cancer. PLoS One 2008;3:e1908.

49. Sun G, Sun L, Liu Y, Xing H, Wang K. Her-2 expression regulated by downregulation of miR-9 and which affects chemotherapeutic effect in breast cancer. Cancer Gene Ther 2017;24:194-202.

50. Gezer U, Keskin S, Igci A, Tükenmez M, Tiryakioglu D, et al. Abundant circulating microRNAs in breast cancer patients fluctuate considerably during neoadjuvant chemotherapy. Oncol Lett 2014;8:845-8. 
51. Al-Khanbashi M, Caramuta S, Alajmi AM, Al-Haddabi I, Al-Riyami M, et al. Tissue and serum miRNA profile in locally advanced breast cancer (LABC) in response to neo-adjuvant chemotherapy (NAC) treatment. PLoS One 2016;11:e152032.

52. Hu Y, Qiu Y, Yagüe E, Ji W, Liu J, et al. MiRNA-205 targets VEGFA and FGF2 and regulates resistance to chemotherapeutics in breast cancer. Cell Death Dis 2016;7:e2291.

53. Hu H, Li S, Cui X, Lv X, Jiao Y, et al. The overexpression of hypomethylated miR-663 induces chemotherapy resistance in human breast cancer cells by targeting heparin sulfate proteoglycan 2 (HSPG2). J Biol Chem 2013;288:10973-85.

54. Kolacinska A, Morawiec J, Fendler W, Malachowska B, Morawiec Z, et al. Association of microRNAs and pathogenic response to preoperative chemotherapy in triple negative breast cancer: preliminary report. Mol Biol Rep 2014;41:2851-7.

55. García-Vazquez R, Ruiz-Garzía E, García AM, Astudillo-de la Vega H, Lara-Medina F, et al. A microRNA signature associated with pathological complete response to novel neoadjuvant therapy regimen in triple-negative breast cancer. Tumor Biol 2017;39:1010428317702899.

56. Hubaux R, Vandermeers F, Cosse JP, Crisanti C, Kapoor V, et al. Valproic acid improves second-line regimen of small cell lung carcinoma in preclinical models. ERJ Open Res 2015;1:00028-2015.

57. Pan YZ, Gao W, Yu AM. MicroRNAs regulate CYP3A4 expression via direct and indirect targeting. Drug Metab Dispos 2009;37:2112-7.

58. Ravery V, Fizazi K, Oudard S, Drouet L, Eymard JC, et al. The use of estramustine phosphate in the modern management of advanced prostate cancer. BJU Int 2011;108:1782-6.

59. Wei C, Pan Y, Huang H, Li YP. Estramustine phosphate induces prostate cancer cell line PC3 apoptosis by down-regulating miR-31 levels. Eur Rev Med Pharmacol Sci 2018;22:40-5.

60. Lin X, Wang Y. Re-expression of microRNA-4319 inhibits growth of prostate cancer via Her-2 suppression. Clin Transl Oncol 2018;20:1400-7.

61. Teimouri F, Nikfar S, Abdollahi M. Efficacy and side effects of dacarbazine in comparison with temozolomide in the treatment of malignant melanoma: a meta-analysis consisting of 1314 patients. Melanoma Res 2013;23:381-9.

62. Zhu W, Zhou L, Qian JQ, Qiu TZ, Shu YQ, et al. Temozolomide for the treatment of brain metastases: a review of 21 clinical trials. World J Clin Oncol 2014;5:19-27.

63. Newlands ES, Stevens MFG, Wedge SR, Wheelhouse RT, Brock C. Temozolomide: a review of its discovery, chemical properties, preclinical development and clinical trials. Cancer Treat Rev 1997;23:35-61.

64. Chen YN. Dacarbazine inhibits proliferation of melanoma FEMX-1 cells by up-regulating expression of miRNA-200. Eur Rev Med Pharmacol Sci 2017;21:1191-7.

65. Jones K, Nourse JP, Keane C, Bhatnagar A, Gandhi MK. Plasma microRNA are disease response biomarkers in classical Hodgkin lymphoma. Clin Cancer Res 2013;20:253-64.

66. Shi L, Chen J, Yang J, Pan T, Zhang S, et al. MiR-21 protected human glioblastoma U78MG cells from chemotherapeutic drug temozolomide induced apoptosis be decreasing Bax/Bcl-2 ratio and caspase-3 activity. Brain Res 2010;1352:255-64.

67. Zhang S, Wan Y, Pan T, Gu X, Qian C, et al. MicroRNA-21 inhibitor sensitizes human glioblastoma U251 stem cells to chemotherapeutic drug temozolomide. J Mol Neurosci 2012;47:346-56.

68. Wong ST, Zhang XQ, Zhuang JT, Chan HL, Li CH, et al. MicroRNA-21 inhibition enhances in vitro chemosensitivity of temozolomideresistant glioblastoma cells. Anticancer Res 2012;32:2835-41.

69. Gwak HS, Kim TH, Jo GH, Kim YJ, Kwak HJ, et al. Silencing of microRNA-21 confers radio-sensitivity through inhibition of the PI3K/AKT pathway and enhancing autophagy in malignant glioma cell lines. PLoS One 2012;7:e47449.

70. Comincini S, Allavena G, Palumbo S, Morini M, Durando F, et al. MicroRNA-17 regulates the expression of ATG7 and modulates the autophagy process, improving the sensitivity to temozolomide and low-dose ionizing radiation treatments in human glioblastoma cells. Cancer Biol Ther 2013;14:574-86.

71. Ananta JS, Paulmurugan R, Massoud TF. Nanoparticle-delivered antisense microRNA-21 enhances the effects of temozolomide on glioblastoma. Mol Pharmaceutics 2015;12:4509-17.

72. Ujifuku K, Mitsutake N, Takakura S, Matsuse M, Saenko V, et al. MiR-195, miR-455-3p and miR-10a(*) are implicated in acquired temozolomide resistance in glioblastoma multiforme cells. Cancer Lett 2010;296:241-8.

73. Tezcan G, Tunca B, Bekar A, Preusser M, Berghoff AS, et al. MicroRNA expression pattern modulates temozolomide response in GBM tumors with cancer stem cells. Cell Mol Neurobiol 2014;34:679-92.

74. Cirilo PDR, de Sousa Andrade LN, Corrêa BRS, Qiao M, Furuya TK, et al. MicroRNA-195 acts as an anti-proliferative miRNA in human melanoma cells by targeting prohibitin 1. BMC Cancer 2017;17:750.

75. Munoz JL, Rodriguez-Cruz V, Rameshwar P. High expression of miR-9 in CD133(+) glioblastoma cells in chemoresistance to temozolomide. J Cancer Stem Cell Res 2015;3:e1003.

76. Munoz JL, Rodriguez-Cruz V, Ramkissoon SH, Ligon KL, Greco SJ, et al. Temozolomide resistance in glioblastoma occurs by miRNA9-targeted PTCH1, independent of sonic hedgehog level. Oncotarget 2015;6:1190-201.

77. Stojcheva N, Schechtmann G, Sass S, Roth P, Florea AM, et al. MicroRNA-138 promotes acquired alkylator resistance in glioblastoma by targeting the Bcl-2-interacting mediator BIM. Oncotarget 2016;7:12937-50.

78. Han J, Chen Q. MiR-16 modulate temozolomide resistance by regulating BCL-2 in human glioma cells. Int J Clin Exp Pathol 2015;8:12698-707.

79. Luo H, Chen Z, Wang S, Zhang R, Qiu W, et al. C-Myc-miR-29c-REV3L signaling pathway drives the acquisition of temozolomide resistance in glioblastoma. Brain 2015;138:3654-72.

80. Xiao S, Yang X, Qiu X, Lv R, Liu J, et al. MiR-29c contribute to glioma cells temozolomide sensitivity by targeting O6-methylgunine- 
DNA methyltransferases indirectly. Oncotarget 2016;7:50229-38.

81. Xu J, Huang H, Peng R, Ding X, Jiang B, et al. MicroRNA-30a increases the chemosensitivity of U251 glioblastoma cells to temozolomide by directly targeting beclin 1 and inhibiting autophagy. Exp Ther Med 2018;15:4798-804.

82. Wu H, Liu Q, Cai T, Chen YD, Liao F, et al. MiR-136 modulates glioma cell sensitivity to temozolomide by targeting astrocyte elevated gene-1. Diagn Pathol 2014;9:173.

83. Wang L, Shi ZM, Jiang CF, Liu X, Chen Q, et al. MiR-143 acts as a tumor suppressor by targeting N-RAS and enhances temozolomideinduced apoptosis in glioma. Oncotarget 2014;5:5416-27.

84. Chen R, Liu H, Cheng Q, Jiang B, Peng R, et al. MicroRNA-93 promotes the malignant phenotypes of human glioma cells and induces their chemoresistance to temozolomide. Biol Open 2016;5:669-77.

85. Shi L, Zhang S, Feng K, Wu F, Wan Y, et al. MicroRNA-125b-2 confers human glioblastoma stem cell resistance to temozolomide through the mitochondrial pathway of apoptosis. Int J Oncol 2012;40:119-29.

86. Chen L, Zhang J, Han L, Zhang A, Zhang C, et al. Downregulation of miR-221/222 sensitizes glioma cells to temozolomide by regulating apoptosis independently of the p53 status. Oncol Rep 2012;27:854-60.

87. Zhou X, Wu W, Zeng A, Nie E, Jin X, et al. MicroRNA-141-3p promotes glioma cell growth and temozolomide resistance by directly targeting p53. Oncotarget 2017;8:71080-94.

88. Peng Y, He X, Chen H, Duan H, Shao B, et al. Inhibition of microRNA-299-5p sensitizes glioblastoma cells to temozolomide via the MAPK/ERK signaling pathway. Biosci Rep 2018;38:BSR20181051.

89. Tian T, Mingyi M, Qiu X, Qiu Y. MicroRNA-101 reverses temozolomide resistance by inhibition of GSK3b in glioblastoma. Oncotarget 2016;7:79584-95.

90. Chen PH, Cheng CH, Shih CM, Ho KH, Lin CW, et al. The inhibition of microRNA-128 on IGF-1-activating mTOR signaling involves in temozolomide-induced glioma cell apoptotic death. PLoS One 2016;11:e0167096.

91. Chen H, Li X, Zheng H. MiR-130a can predict response to temozolomide in patients with glioblastoma multiforme, independently of O6-methylguanine-DANN methyltransferase. J Transl Med 2015;13:69.

92. Kushwaha D, Ramakrishnan V, Ng K, Steed T, Nguyen T, et al. A genome-wide miRNA screen revealed miR-603 as a MGMTregulating miRNA in glioblastomas. Oncotarget 2014;5:4026-39.

93. Lee YY, Yarmishyn AA, Wang ML, Chen HY, Chiou SH, et al. MicroRNA-142-3p is involved in regulation of MGMT expression in glioblastoma cells. Cancer Management Res 2018;10:775-85.

94. Kreth S, Limbeck E, Hinske LC, Schütz SV, Thon N, et al. In human glioblastomas transcript elongation by alternative polyadenylation and miRNA targeting is a potent mechanism of MGMT silencing. Acta Neuropathol 2013;125:671-81.

95. Kouri FM, Hurley FA, Daniel WL, Day ES, Hua Y, et al. MiR-182 integrates apoptosis, growth, and differentiation programs in glioblastoma. Genes Dev 2015;29:732-45.

96. Cheng ZX, Yin WB, Wang ZY. MicroRNA-132 induces temozolomide resistance and promotes the formation of cancer stem cell phenotypes by targeting tumor suppressor candidate 3 in glioblastoma. Int J Mol Med 2017;40:1307-14.

97. Gao YT, Chen XB, Liu HL. Up-regulation of miR-370-3p restores glioblastoma multiforme sensitivity to temozolomide by influencing MGMT expression. Sci Rep 2016;6:32972.

98. Li S, Zeng A, Hu Q, Yan W, Liu Y, et al. MiR-423-5p contributes to a malignant phenotype and temozolomide chemoresistance in glioblastomas. Neuro Oncol 2017;19:55-65.

99. Chen HY, Li WB, Zhang CB, Zhang W, Zheng HY. MiR-629-3p level significantly predicts prognosis in glioblastoma patients with temozolomide chemotherapy. Curr Signal Transd Ther 2014;9:9-14.

100. Li XB, Wang J, Xu AD, Huang JM, Meng LQ, et al. The microRNA-1268 rs28599926 polymorphism modified diffusely infiltrating astrocytoma risk and prognosis. Int J Clin Exp Med 2016;9:21615-24.

101. Chen H, Liu L, Li X, Shi Y, Liu N. MicroRNA-1294 inhibits the proliferation and enhances the chemosensitivity of temozolomide via the direct targeting of TPX2. Am J Cancer Res 2018;8:291-301.

102. Ahir BK, Ozer H, Engelhard HH, Lakka SS. MicroRNAs in glioblastoma pathogenesis and therapy: a comprehensive review. Crit Rev Oncol Hematol 2017;120:22-33.

103. Quintavalle C, Mangani D, Roscigno G, Romano G, Diaz-Lagares A, et al. MiR-221/222 target the DNA methyltransferase MGMT in glioma cells. PLoS One 2013;8:e74466.

104. Bassiouny AR, Zaky A. Synergistic effect of curcumin on temozolomide inhibition of cancer stem cell-like properties and reduced chemoresistance of glioblastoma C6. J Stem Cell Res Ther 2012;2:5.

105. Schepartz SA. Early history and development of the nitrosoureas. Cancer Treat Rep 1976;60:647-9.

106. Weiss RB, Issell BF. The nitrosoureas: carmustine (BCNU) and lomustine (CCNU). Cancer Treat Rev 1982;9:313-30.

107. Reithmeier T, Graf E, Piroth T, Trippel M, Pinsker MO, et al. BCNU for recurrent glioblastoma multiforme: efficacy, toxicity and prognostic factors. BMC Cancer 2010;10:30.

108. Kohn KW. Interstrand coss-linking of DNA by 1,3-bis(2-chloroethyl)-1-nitrosourea and other 1-(2-chloroethyl)-1-nitrosoureas. Cancer Res 1977;37:1450-4.

109. Panasci LC, Green D, Nagourney R, Fox P, Schein PS. A structure-activity analysis of chemical and biological parameters of chloroethylnitrosoureas in mice. Cancer Res 1977;37:2615-8.

110. Winkler JA, Hendricks WP, Johnson D, Xia J, Scheck AC. Global microRNA expression analysis in human malignant glioma cells reveals novel miRNA-mediated therapy-resistance mechanisms. Proc Amer Assoc Cancer Res 2005;46:Abstract No 5942.

111. Wang GB, Liu JH, Hu J, Xue K. MiR-21 enhanced glioma cells resistance to carmustine via decreasing Spry2 expression. Eur Rev Med 
Pharmacol Sci 2017;21:5065-71.

112. Sippl C, Ketter R, Bohr L, Kim YJ, List M, et al. MiRNA-181d expression significantly affects treatment responses to carmustine wafer implantation. Neurosurgery 2018; doi:10.1093/neuros/nyy214.

113. Xie Q, Yan Y, Huang Z, Zhong X, Huang L. MicroRNA-221 targeting PI3-K/Akt signaling axis indces cell proliferation and BCNU resistance in human glioblastoma. Neuropathol 2014;34:455-64.

114. Anchel M, Hervey A, Robbins WJ. Antibiotic substances from Basidiomycetes. VII. Clitocybe illudens. Proc Natl Acad Sci 1950;6:30-6.

115. Crooke ST, Bradner WT. Mitomycin C: a review. Cancer Treat Rev 1976;3:121-39.

116. Hata T, Sugawara R. Mitomycin, a new antibiotic from Streptomyces. II. Description of the strain. J Antibiot 1956;9:147-51.

117. Wakaki S, Marumo H, Tomioka K, Shimizu G, Kato E, et al. Isolation of new fractions of antitumor mitomycins. Antibiotics Chemother 1958;8:228-40.

118. Frank W, Osterberg AE. Mitomycin C: a evaluation of the Japanese reports. Cancer Chemother Rep 1960;9:114-9.

119. Bradner WT. Mitomycin C: a clinical update. Cancer Treat Rev 2001;27:35-50.

120. Tomasz M. Mitomycin C: small, fast and deadly (but very selective). Chem Biol 1995;2:575-9.

121. Feist M, Huang X, Müller JM, Rau B, Dubiel W. Can hyperthermic intraperitoneal chemotherapy efficiency be improved by blocking the DNA repair factor COP9 signalosome? Int J Colorectal Dis 2014;29:673-80.

122. Xu T, Qin L, Zhu Z, Wang X, Liu Y, et al. MicroRNA-31 functions as a tumor suppressor and increases sensitivity to mitomycin-C in urothelial bladder cancer by targeting integrin $\alpha 5$. Oncotarget 2016;7:27445-57.

123. Weeraratne SD, Amani V, Neiss A, Teider N, Scott DK, et al. MiR-34a confers chemosensitivity through modulation of MAGE-A and p53 in medulloblastoma. Neuro Oncol 2011;13:165-75.

124. Sharma S, Nagpal N, Ghosh PC, Kulshreshtha R. p53-miR-191-SOX4 regulatory loop affects apoptosis in breast cancer. RNA 2017;23:1237-46.

125. Mezencev R, Matyunina LV, Jabbari N, McDonald JF. Snail-induced epithelial-to-mesenchymal transition of MCF-7 breast cancer cells: systems analysis of molecular changes and their effect on radiation and drug sensitivity. BMC Cancer 2016;16:236.

126. Lee S, Yu KR, Ryu YS, Oh YS, Hong IS, et al. MiR-543 and miR-590-3p regulate human mesenchymal stem cell aging via direct targeting of AIMP3/p18. AGE 2014;36:9724

127. Xu K, Liang X, Cui D, Wu Y, Shi W, et al. MiR-1915 inhibits Bcl-2 to modulate multidrug resistance by increasing drug-sensitivity in human colorectal carcinoma cells. Mol Carcinogen 2013;52:70-8.

128. Tarasov VA, Matishov DG, Shin EF, Boyko NV, Timoshkina NN, et al. Inheritable changes in miRNAs expression in HeLa cells after X-ray and mitomycin C treatment. Russ J Gen 2014;50:798-806.

129. Le VH, Inai M, Williams RM, Kan T. Ecteinascidins. A review of the chemistry, biology and clinical utility of potent tetrahydroisoquinoline antitumor antibiotics. Nat Prod Rep 2015;32:328-47.

130. Jaspers NG, Raams A, Kelner MJ, Ng JM, Yamashita YM, et al. Anti-tumour compounds illudin S and irofulven induce DNA lesions ignored by global repair and exclusively processed by transcription- and replication-coupled repair pathways. DNA Repair 2002;1:1027-38

131. Forni C, Minuzzo M, Virdis E, Tamborini E, Simone M, et al. Trabectedin (ET-743) promotes differentiation in myxoid liposarcoma tumors. Mol Cancer Ther 2009;8:449-57.

132. Uboldi S, Calura E, Beltrame L, Nerini IF, Marchini S, et al. A systems biology approach to characterize the regulatory networks leading to trabectedin resistance in an in vitro model of myxoid liposarcoma. PLoS One 2012;7:e35423.

133. Neia CP, Cavalloni G, Chiorino G, Ostano P, Aglietta M, et al. Gene and microRNA modulation upon trabectedin treatment in a human intrahepatic cholangiocarcinoma paired patient derived xenograft and cell line. Oncotarget 2016;7:86766-80. 